\title{
Management of infertility
}

\author{
Adam H Balen, ${ }^{1}$ Anthony J Rutherford ${ }^{1}$
}

Leeds General Infirmary,

Leeds LS2 9NS

Correspondence to: A H Balen

adam.balen@leedsth.nhs.uk

BMJ 2007;335:608-11

doi:10.1136/bmj.39324.662049.80
Around 9\% of couples are involuntarily childless. At least a quarter of couples experience unexpected delays in achieving their desired family size,${ }^{1}$ although only a half seek treatment. In recent years, publicity about infertility treatments has increased, and couples are now more willing to seek advice. The first of these two brief reviews covers the main causes of infertility, with particular reference to advances in the past five years; the second review will look at polycystic ovary syndrome and anovulatory infertility.

The role of the general practitioner is to initiate the investigation of both partners and ensure timely onward referral to a specialist clinic. Treatments for infertility are never far from the public eye, often courting controversy and ethical dilemmas. This article aims to provide general practitioners with a balanced and evidence based overview of the latest advances and where they fit into current practice.

\section{Sources and selection criteria}

We referred to the Cochrane database of systematic reviews, NICE guidelines for the investigation and management of infertility (2004), and our knowledge of the current literature.

\section{What is the effect of age on fertility?}

The most important determinant of a couple's fertility is the woman's age (fig 1). For women up to 25 the cumulative conception rate is $60 \%$ at six months and $85 \%$ at a year, but conception rates are more than halved by 35 or over. ${ }^{1}$ The finite number of oocytes means that age reduces fertility and increases the risk of congenital abnormalities. ${ }^{23}$

Male fertility also declines with age, most noticeably after the age of 55 , with a concomitant increase in chromosomal anomalies in offspring. ${ }^{34}$ Even men older than 35 have half the chance of achieving a pregnancy compared with men younger than $25 .^{5}$

\section{Does environmental pollution affect male fertility?}

A decline in male fertility has been reported in several countries, although this is controversial, ${ }^{6}$ and more longitudinal studies are needed. A decline in sperm density is occurring at the same time as an increase in the incidence of testicular cancer and the frequency of hypospadias and cryptorchidism. Environmental pollution-possibly arising from oestrogenic industrial waste - is a likely cause. In a prospective observational study, organic farmers who were asked to provide semen samples were found to have significantly higher sperm concentrations than printers, electricians, or metal workers, ${ }^{7}$ which lends further credence to the possible effects of environmental toxins.

\section{Can women predict their fertility?}

A secular change has occurred in family planningthe mean age of mothers at first birth in Western countries is now around 29.5 years, as opposed to 25 years two decades ago. ${ }^{3}$ The risks of complications in pregnancy rise significantly with increasing maternal age. ${ }^{8}$

How reliable are ovarian reserve tests?

Women often wish to have an idea of their potential fertility. The concentration of serum follicle stimulating hormone (FSH) measured during the first three days of menstruation is the most commonly used test of "ovarian reserve"- a term that refers to the number of oocytes in the ovary and their fertility potential. Other measurements may increase the positive predictive value of follicle stimulating hormone, including an ultrasound scan to measure ovarian volume and the number of antral follicles, serum inhibin B concentration, and anti-Mullerian hormone (AMH) concentration. ${ }^{9}$ It has been suggested that these tests may help determine a woman's future natural fertility, although evidence for longer term predictions is lacking and the use of ovarian reserve testing outside of the context of planning infertility treatment is unclear. ${ }^{10}$

\section{Can women protect their fertility?}

Techniques have been developed for cryopreserving oocytes and ovarian tissue in women who have

\section{ONGOING RESEARCH QUESTIONS AND PROJECTS}

- How can we increase the success rate of assisted conception while minimising the risks of multiple pregnancy by the transfer of single embryos?

- How can fertility be preserved in the context of cancer treatments that cause sterility or as insurance against ageing?

- Monitoring the long term health of children conceived by assisted conception treatments

- Monitoring the long term health of women who have received ovarian stimulation for induction of ovulation or assisted conception 


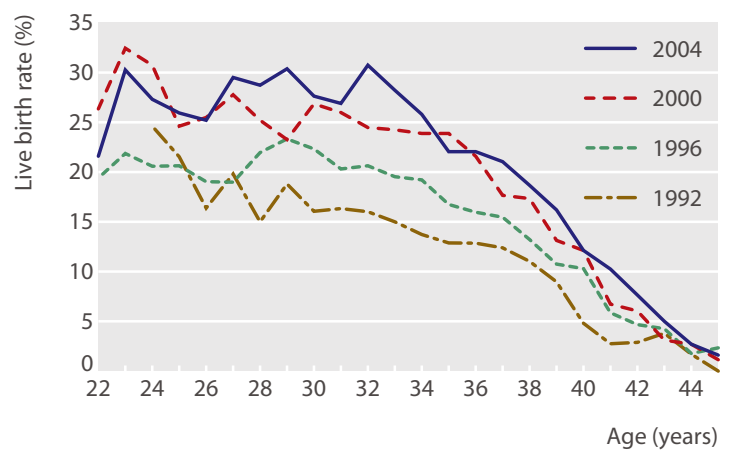

Fig 1 | Live birth rates per cycle started for in vitro fertilisation in the $\mathrm{UK}^{2}$

treatments for cancer that result in sterility. This has raised interest in the idea that women who have yet to find a partner or who wish to pursue a career could bank oocytes when young for future use. Unfortunately, however, these techniques are still relatively inefficient. To freeze oocytes, women have to undergo the same stimulation as when having in vitro fertilisation, the survival rate is relatively low, and subsequent fertilisation and pregnancy are not guaranteed. On average, using standard stimulation regimens, eight to 12 mature oocytes are produced per cycle, which currently provides a modest live birth rate of $18.3 \%$ much lower than with conventional in vitro fertilisation. ${ }^{11}$ Strips of ovarian cortex containing oocytes have been cryopreserved before giving women sterilising chemotherapy for cancer. ${ }^{12} \mathrm{Up}$ to $75 \%$ of oocytes are lost as part of the freezing, thawing, and grafting process however, so this technique should be reserved for women in whom no alternative exists, especially as a whole ovary is normally needed. ${ }^{12}$

How can we protect against sexually transmitted diseases? Sexually transmitted infections are a preventable cause of infertility. In the United Kingdom, we have failed to achieve a successful sexual health education

\section{Box 1 Investigations for infertility in primary care (based on NICE guidance) ${ }^{14}$}

\section{Female partner}

- Full examination including assessment of body mass index

- Baseline endocrinology on days 1-3 of menstrual cycle: measure follicle stimulating hormone and luteinising hormone to assess ovarian function. Measure mid-luteal (seven days before expected menstruation) progesterone to confirm ovulation. If the menstrual cycle is irregular, assess prolactin and thyroid function plus testosterone if the patient has signs of hyperandrogenism (symptoms of polycystic ovary syndrome: acne, hirsutism, alopecia). Additional tests of ovarian reserve possible (see text)

- Confirm rubella immunity

- Cervical cytology and screening for Chlamydia trachomatis and other genital infections, particularly before assessing tubal patency

- Imaging of pelvis (secondary care): ultrasound to assess ovarian and uterine morphology. $X$ ray hysterosalpingography to assess tubal patency if no history suggestive of tubal or gynaecological disease otherwise laparoscopic assessment of pelvis with facility to treat (endometriosis or tubal adhesions)

\section{Male partner}

- Semen analysis, performed twice after two to three days of abstinence from sex programme, so that our adolescent population has an ever rising rate of chlamydial infections and other sexually transmitted diseases, unwanted pregnancies, and the risks associated with abortion. ${ }^{13}$ The efficacy of population screening for Chlamydia to prevent infertility is unclear. Education about family planning should deal with protecting future fertility, not just preventing unwanted pregnancy.

\section{When should you investigate infertility?}

The NICE guidelines for the assessment and treatment of people with fertility problems ${ }^{14}$ define infertility as "failure to conceive after regular unprotected sexual intercourse for two years in the absence of known reproductive pathology," although they suggest that patients should be offered tests after one year. If the woman has a history of irregular periods, pelvic inflammatory disease, or appendicitis causing peritonitis, or the man has a history of orchitis or cryptorchidism, testing should begin at an earlier date. Box 1 summarises the recommended investigations for both men and women, and box 2 provides the normal parameters for semen.

\section{What are the principles of treatment?}

The first principle of fertility treatment is that the interests of the unborn child must be foremost. Thus, at the infertility consultation advice should be given about preparation for pregnancy, both physical (diet, alcohol consumption, smoking, etc; box 3$)^{16}$ and psychological (the need for counselling).

Because multiple pregnancy can have such devastating effects, both in terms of the obstetric outcome and the effect on the life of the family, as much effort should be invested in the safety of treatment as in its efficacy. Because people have such high expectations of fertility treatment, some couples find it almost impossible to face the possibility that they might not have children. Therefore, even in these cost containing days of efficiency based medicine, people with a poor prognosis should still be offered some form of treatment. Indeed, we offer some treatment even when the chances of success are slim after appropriate informed discussion, to

Box 2 | Normal semen parameters ${ }^{15}$

- Volume $\geq 2.0 \mathrm{ml}$

- $\mathrm{pH}$ 7.2-8.0

- Sperm concentration $\geq 20 \times 10^{6} / \mathrm{ml}$

- Total sperm count $\geq 40 \times 10^{6} /$ ejaculate

- Motility (within 60 min of ejaculation)

$\geq 25 \%$ with rapid progression (category "a")

$\geq 50 \%$ with forward progression (categories "a" and "b")

- Vitality

$\geq 75 \%$ live (categories "a", "b", and "c")

$\leq 25 \%$ dead (category "d")

- Morphology $\geq 30 \%$ normal forms

- White blood cells $<1 \times 10^{6} / \mathrm{ml}$

- Immunobead test and mixed antiglobulin reaction for antisperm antibodies $<50 \%$ 
Box 3 | Lifestyle advice for men and women ${ }^{14}$

Avoid smoking, minimise alcohol consumption (preferably zero for women), achieve normal weight for height (obesity affects both male and female fertility), take regular cardiovascular exercise (20-30 minutes each day)

Women should take folic acid supplements to reduce neural tube defects. Other vitamin supplements are of doubtful benefit for either sex. Some advocate zinc, selenium, and vitamin E supplements for men with abnormal semen parameters of unknown cause, although the evidence for efficacy is weak

help couples to resolve their "fertility wish" without regrets in the future. With all treatments we should of course be aware of the psychological and social pressures and consider a formal evaluation of health related quality of life. ${ }^{17}$

\section{What's new in assisted conception treatments?}

Almost three decades since the birth of Louise Brown (the first baby born after in vitro fertilisation) the role of assisted conception treatment has expanded considerably. The original indications for in vitro fertilisation were mechanical obstruction to fertility, mostly tubal damage, endometriosis, and, less often, fibroids (the management of which is covered in the NICE guidance) ${ }^{14}$ Intracytoplasmic sperm injection (ICSI), which now accounts for around $40 \%$ of in vitro fertilisation treatments, has revolutionised the management of male factor infertility, for which there are few other options if men wish to have their own genetic child. Modifications to the treatment, from superovulation strategies to generate more mature oocytes, through to advances in culture technology that allow embryos to thrive in the laboratory, have led to a steady increase in live births over the past 20 years - currently greater than $25 \%$ per cycle in the UK. ${ }^{18}$ About 30000 assisted conceptions are performed annually in the UK and these are responsible for about $1 \%$ of all births (fig 2). ${ }^{18}$ Despite NICE recommendations that all couples should be offered three complete cycles to provide a realistic opportunity to conceive,${ }^{14}$ most primary care trusts still only provide one - if any-treatment per couple. ${ }^{19}$ This puts the UK 17 th out of 23 for fertility treatment funded by the state in Europe.

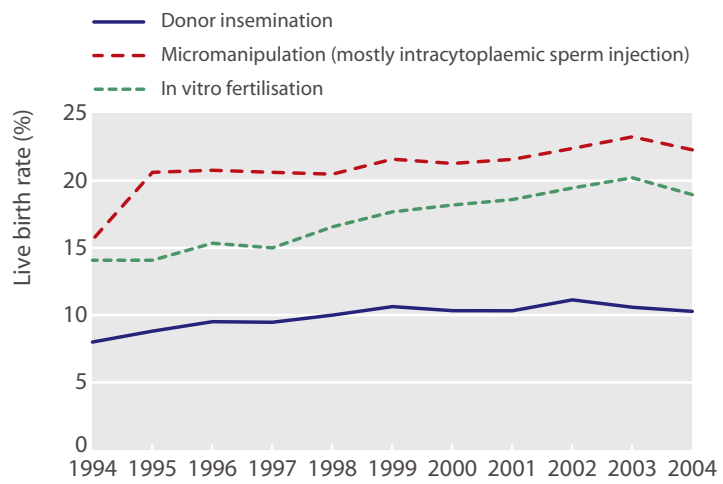

\section{The problem of multiple pregnancies}

A major problem of the growth of assisted conception is the dramatic rise in multiple births (fig 3). Legislation introduced by the Human Fertilisation and Embryology Authority (HFEA) in 2002 limits the number of embryos transferred to two for women under 40. This has prevented the birth of triplets (and greater), but the number of twin pregnancies has not declined. In Belgium, state funding is dependent on a stringent embryo replacement policy-all good candidates (young patients under 35 in their first cycle) are limited to a single embryo. A voluntary reduction to a single embryo transfer policy in Sweden led to a significant fall in multiple pregnancies while maintaining the overall live birth rate. ${ }^{20}$ Evidence suggests that by adopting a single embryo transfer policy and cryopreserving the spare embryos for subsequent replacement if the initial cycle fails, the live birth rate is not significantly different from that after a double embryo transfer. ${ }^{21}$

A recent report suggested that a less aggressive ovarian stimulation policy and single embryo transfer was as successful and more cost effective than a conventional superovulation protocol and double embryo transfer over four cycles, taking into account the neonatal costs of twin pregnancies. ${ }^{22}$ A report published by the Human Fertilisation and Embryology Authority recommended strongly that a single embryo transfer policy be introduced in the UK. ${ }^{21}$ The only way that this is likely to be achieved is through regulation, and to be equitable this must be accompanied by better National Health Service funding.

\section{New advances in in vitro fertilisation}

Most unsuccessful in vitro fertilisation cycles fail after embryo transfer, so research has focused on trying to identify the best embryos to transfer. Non-invasive ways to assess the embryo's health have looked at the embryo's metabolism - in particular the amino acid profile. ${ }^{23}$ Metabolically quiet embryos are more likely to develop than those with a high amino acid turnover. Research is currently exploring whether these initial results can be translated into a valuable clinical tool.

Many embryos are karyotypically abnormal, and the proportion increases greatly with age.

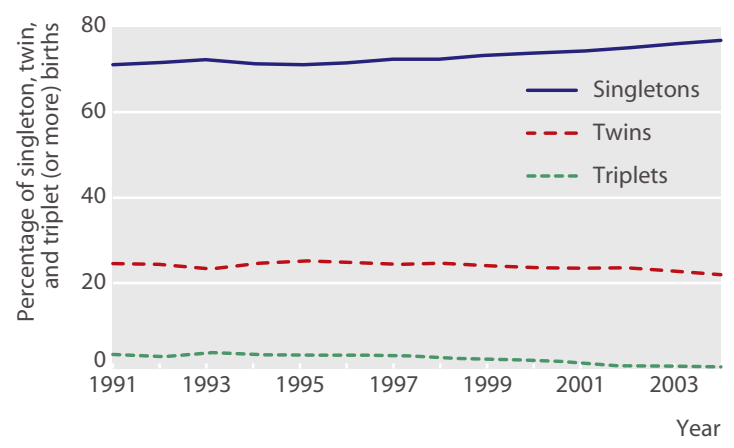

Fig 3 Singleton, twin, and triplet births as a percentage of all live births after in vitro fertilisation in the UK ${ }^{18}$ 


\section{SUMMARY POINTS}

- Around $9 \%$ of couples are affected by infertility and half of them seek help

- The most important determinant of a couple's fertility is the woman's age

- Demographic trends to delay childbearing mean that more older women are having problems trying to conceive

- Lifestyle has a profound effect on fertility—obesity, smoking, alcohol, and recreational drugs negatively affect the chance of conception and pregnancy outcome

- Male infertility may be increasing, possibly because of environmental pollution

- Success rates of in vitro fertilisation may improve with a better understanding of embryo physiology

Preimplantation genetic screening of patients at highest risk of aneuploidy has been considered..$^{24}$ One cell is removed from a six to eight cell, three day old embryo and tested for the six chromosomes most likely to cause miscarriage. Unfortunately, studies to date have failed to show that this has any effect on the live birth rate.

\section{Conclusions}

We have deliberately not provided algorithms for the management of infertility, which have been amply covered elsewhere. ${ }^{25}$ Whole reviews have been written on each topic, and we have tried to refer to some of the latest papers. We have dealt mainly with conditions that affect female fertility as these tend to be more amenable to treatment, whereas for most men with subfertility the problem is managed with assisted conception treatments, such as intracytoplasmic sperm injection or the use of donated sperm when azoospermia exists. Recent changes in the lifestyle of the population have undoubtedly had a profound effect on fertility, whether as a result of the increased tendency to delay childbearing or increasing rates of sexually transmitted infections and obesity. Better health education is a prerequisite for improving the fertility prospects of the next generation.

Contributors: AHB conceived the outline of the review and wrote the body of the text with contributions and advice from AJR. AHB is guarantor.

\section{ADDITIONAL EDUCATIONAL RESOURCES}

\section{Resources for health professionals}

Balen AH, Jacobs HS. Infertility in practice. 2nd ed. London: Churchill Livingstone/ Harcourt Brace, 2003

British Fertility Society_A national multidisciplinary organisation representing professionals practising in reproductive medicine (www.britishfertilitysociety.org.uk/) European Society of Human Reproduction and Embryology-Facilitates research and dissemination of findings in human reproduction and embryology (http://www.eshre. $\mathrm{com} /$ )

Human Fertilisation and Embryology Authority-Independent regulator that oversees safe and appropriate practice in fertility treatment and embryo research in the UK (http://www.hfea.gov.uk)

Cochrane Database of Systematic Reviews-Contains reviews on various aspects of infertility management (www.mrw.interscience.wiley.com/cochrane/

cochrane_clsysrev_articles_fs.html)

\section{Resources for patients}

Infertility Network UK-National UK patient support organisation for couples with infertility (www.infertilitynetworkuk.com)
Competing interests: None declared.

Provenance and peer review: Commissioned; externally peer reviewed.

1 Boivin J, Bunting L, Collins JA, Nygren KG. International estimates of infertility prevalence and treatment seeking: potential need and demand for infertility medical care. Hum Reprod 2007;22:1506-12.

2 Human Fertilisation and Embryology Authority. A longterm analysis of register data 1991-2006, version I. 2007. www.hfea.gov.uk/docs/ Latest_long_term_data_analysis_report_front_cover.pdf.

3 ESHRE Capri Workshop Group. Fertility and ageing. Human Reprod Update 2005;11:261-76.

4 Eskenazi B, Wyrobek AJ, Sloter E, Kidd SA, Moore L, Young S, et al. The association of age and semen quality in healthy men. Human Reprod 2003;18:447-54

5 Ford WC, North K, Taylor H, Farrow A, Hull MG, Golding J. Increasing paternal age is associated with delayed conception in a large population of fertile couples: evidence for declining fecundity in older men. The ALSPAC study team (Avon longitudinal study of pregnancy and childhood). Hum Reprod 2000;15:1703-8.

6 Jorgensen N, Andersen A-G, Eustache F, Irvine DS, Suominen J, Petersen $\mathrm{JH}$, et al. Regional differences in semen quality in Europe. Hum Reprod 2001;16:1012-9.

7 Abell A, Ernst E, Bonde JP. High sperm density among members of organic farmers' association. Lancet 1994:343:1498.

8 Luke B, Brown MB. Elevated risks of pregnancy complications and adverse outcomes with increasing maternal age. Hum Reprod 2007;22:1264-72.

9 Broekmans FJ, Kwee J, Hendricks DJ, Mol BW, Lambalk CB. A systematic review of test predicting ovarian reserve and IVF outcome. Hum Reprod Update 2006;12:685-718.

10 Maheshwari A, Fowler P, Bhattacharya S. Assessment of ovarian reserve-should we perform tests of ovarian reserve routinely? Hum Reprod 2006;11:2729-35.

11 Oktay K, Pelin Cil A, Bang H. Efficiency of oocyte cryopreservation: a meta analysis. Fertil Steril 2007;86:70-80.

12 Meirow D, Levron J, Eldar-Geva T, Hardan I, Fridman E, Yemini Z, et al. Monitoring the ovaries after autotransplantation of cryopreserved ovarian tissue: endocrine studies, in vitro fertilisation cycles, and live birth. Fertil Steril 2007;87:418.e7-15.

13 Cassell JA, Mercer CH, Sutcliffe L, Petersen I, Islam A, Brook MG, et al. Trends in sexually transmitted infections in general practice 19902000: population based study using data from the UK general practice research database. BMJ 2006;332:332-4.

14 National Institute for Health and Clinical Excellence. Fertility: assessment and treatment for people with fertility problems. 2004. www.nice.org.uk/download.aspx?o=104459.

15 World Health Organization. WHO laboratory manual for the examination of human semen and sperm-cervical mucus interaction. Cambridge: Cambridge University Press, 2000.

16 Homan GF, Davies M, Norman R. The impact of lifestyle factors on reproductive performance in the general population and those undergoing infertility treatment: a review. Hum Reprod Update 2007;13:209-23.

17 Jones GL, Kennedy SH, Jenkinson C. Health-related quality of life measurement in women with common benign gynaecologic conditions: a systematic review. Am J Obstet Gynecol 2002;187:501-11.

18 Human Fertilisation and Embryology Authority. National IVF live birth rates—guide to infertility 2006-2007. 2007. www.hfea.gov.uk/docs/ facts_and_figures.pdf.

19 Kennedy R, Kingsland C, Rutherford A, Hamilton M, Ledger W. Implementation of the NICE guideline-recommendations from the British Fertility Society for national criteria for NHS funding of assisted conception. Hum Fertil 2006;9:181-9.

20 Thurin MD, Hausken MD, Hillensjo T, Jablonowska B, Pinborg A, Strandell A, et al. Elective single embryo transfer versus doubleembryo transfer in in vitro fertilisation. $N$ Engl J Med 2004;351:2392-402.

21 Human Fertilisation and Embryology Authority. One child at a time: reducing multiple births after IVF. Report of the Expert Group on Multiple Births after IVF. 2006. HFEA, 2006. www.hfea.gov.uk/docs/ MBSET_report_Final_Dec_06.pdf.

22 Heijnen EMEW, Eijkemans MJC, de Klerk C, Polinder S, Beckers NGM, Klinkert ER, et al. A mild treatment strategy for in-vitro fertilization: a randomized non-inferiority trial. Lancet 2007;368:743-9.

23 Brison DR, Houghton FD, Falconer D, Roberts SA, Hawkhead J, Humpherson PG, et al. Identification of viable embryos in IVF by noninvasive measurement of amino acid turnover. Hum Reprod 2004;19:2319-24.

24 Twisk M, Mastenbroek S, van Wely M, Heineman MJ, Van der Veen F, Repping S. Preimplantation genetic screening for abnormal number of chromosomes (aneuploidies) in in vitro fertilization or intracytoplasmic sperm injection. Cochrane Database Syst Rev 2006; (1):CD005291.

25 Taylor A, Braude P. ABC of subfertility. BMJ 2003;327:434-6. 